\title{
Dextran-Conjugated Anti-Immunoglobulin Antibodies: A Powerful Tool for Studying B Cell Receptor-Mediated Signaling
}

Clifford M Snapper*

Department of Pathology, Uniformed Services University of the Health Sciences, USA

${ }^{*}$ Corresponding author: Clifford M Snapper, Department of Pathology, Uniformed Services University of the Health Sciences, 4301 Jones Bridge, Bethesda, Maryland 20814, USA, Tel: 301-295-3490, Fax: 301-295-1640, E-mail: clifford.snapper@usuhs.edu

\begin{abstract}
Dextran-conjugated anti-immunoglobulin (Ig) antibodies (anti-lgdex) consist of a high molecular weight dextran $\left(\sim 1-2 \times 10^{6} \mathrm{MW}\right)$ to which multiple monoclonal anti-IgM or anti-lgD antibodies are covalently linked. These soluble conjugates have been used in a process of discovery, in extensive studies of in vitro polyclonal murine and human B cell activation, proliferation, Ig secretion and class switching, through signaling via multivalent cross-linking of $B$ cell receptors (BCR) on the B cell surface, in the presence of a multiplicity of added stimuli. The cross-linking of the BCR in a multivalent fashion represents a more physiologic means, relative to using unconjugated bivalent anti-lg, for studying the functional consequences of B cell encounter with specific antigens in vivo. This reflects either the repeating epitope nature of polysaccharides, or the display of a given intact protein in multiple copies on the surface of follicular dendritic cells, macrophages and dendritic cells where they are encountered by B cells.
\end{abstract}

\section{Keywords}

Dextran-anti-IgM, Dextran anti-IgD, B cell receptor, Immunoglobulin Cytokine, Toll-like receptor, Immunoglobulin class switching, Polysaccharide, T cell-independent, T cell-dependent

\section{Introduction}

Anti-Ig-dex was originally conceived as a means for modeling BCR-mediated B cell activation in response to polysaccharides [1]. Polysaccharides consist of long chains of repeating sugars that are capable of multivalent cross-linking of BCR on the surface of polysaccharide-specific B cells [2]. Normal B cells of a given antigenspecificity are present in the host at frequencies so low that studying the behavior of such B cells is highly challenging technically. However, the conjugation of multiple anti-murine or anti-human Ig antibodies to a high molecular weight polysaccharide such as dextran allows for the highly efficient study of multivalent BCR cross linking, as they can engage virtually all normal $B$ cells derived from the host. It is now appreciated that B cells specific for a given peptide epitope, typically expressed as a single, unique structure within a larger protein antigen, are also likely to be activated through multivalent BCR cross linking in vivo, since such B cells typically encounter multiple copies of the same intact protein antigen on the surface of macrophages, dendritic cells, or follicular dendritic cells following immunization or infection [3]. The nature of the signaling mediated by multivalent BCR cross linking in response to polysaccharides versus proteins in vivo may potentially differ in some significant ways, although this needs further study. The relatively low, more physiologic concentrations $(\mathrm{pg} / \mathrm{ml})$ of anti-Ig that are sufficient for optimal B cell activation when anti-Ig is linked to dextran, as opposed to that required using unconjugated anti-Ig antibodies $(\mu \mathrm{g} / \mathrm{ml})$ further underscores the physiologic nature of the anti-Ig-dex model system. Thus, soluble, unconjugated (bivalent) anti-IgM or anti-IgD molecules, often used to study BCRmediated B cell activation, and requiring $\mu \mathrm{g} / \mathrm{ml}$ concentrations of anti-Ig for functional effects, do not model normal B cell physiology. The same argument could be additionally made for anti-Ig antibodies covalently linked to rigid particles, such as sepharose.

Earliest studies using anti-Ig-dextran versus unconjugated anti-Ig underscore marked differences in the induction of intracellular $\mathrm{Ca} 2+$, generation of inositol phosphates, and/ or mitogenesis in mouse and human B cells in vitro

Anti-murine IgM and anti-murine IgD antibodies conjugated to either high MW dextran or Ficoll induced 10-fold greater levels of proliferation at $1000-10,000$-fold lower $(\mathrm{pg} / \mathrm{ml})$ concentrations of anti-Ig relative to unconjugated anti-Ig antibodies [1]. Of note, conjugation of even non-mitogenic monovalent Fab fragments of anti-IgD or non-mitogenic bivalent anti-IgM to dextran rendered them highly mitogenic. The low concentrations of anti-Ig required for anti-Ig-dex-mediated mitogenesis was associated with little modulation of membrane Ig from the B cell surface, and thus the ability to mediate repetitive signaling, in contrast to unconjugated anti-Ig antibodies [4]. In biochemical studies, anti-Ig-dex was observed to induce higher levels of intracellular ionized calcium and total inositol phosphates relative to unconjugated anti-Ig, and the patterns of inositol phosphates generated also differed [5].

In a follow-up study, multiple copies of a monoclonal antihuman IgM antibody was conjugated to high MW dextran $\left(2 \times 10^{6}\right.$ MW) [6]. This dextran conjugate stimulated comparable levels of DNA synthesis and size increases in normal human B cells as that seen with unconjugated anti-human IgM, but at 100- to 1000 -fold lower concentrations of anti-IgM antibody. Anti-human IgM-dex

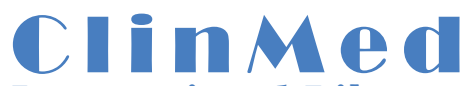

International Library

Citation: Snapper CM (2016) Dextran-Conjugated Anti-Immunoglobulin Antibodies: A Powerful Tool for Studying B Cell Receptor-Mediated Signaling. Int J Immunol Immunother 3:022

Received: March 22, 2016: Accepted: July 30, 2016: Published: August 03, 2016 Copyright: () 2016 Snapper CM. This is an open-access article distributed under the terms of the Creative Commons Attribution License, which permits unrestricted use, distribution, and reproduction in any medium, provided the original author and source are credited. 
also stimulated increases in intracellular ionized calcium in a higher percentage of human B cells, with greater magnitude and of longer duration relative to that stimulated by unconjugated anti-IgM. These data were thus similar to that observed earlier using murine B cells.

The potency of anti-Ig-dex is due to its ability to cluster multiple membrane BCRs for efficient signaling at very low concentrations of anti-Ig, and thus with minimal modulation of BCR from the cell surface, allowing for repetitive signaling. These data were consistent with studies by H. M. Dintzis and colleagues that a minimum of 10 20 membrane Ig receptors per multivalent antigen molecule must be cross-linked (the "immunon") for T cell-independent-mediated B cell activation to occur $[7,8]$.

\section{Anti-Ig-dex co-stimulates Ig secretion in murine B cells in the presence of diverse stimuli}

Unconjugated monoclonal anti-IgM and anti-IgD antibodies stimulate B cell proliferation only when used at high $(\mu \mathrm{g} / \mathrm{ml})$ concentrations. Under these circumstances, large numbers of membrane Ig molecules are rapidly and non-physiologically modulated from the B cell surface by the bound anti-Ig, and internalized, resulting in the termination of BCR signaling. This likely underlies the poor ability of unconjugated anti-Ig to co-stimulate downstream events such as Ig secretion and class switching. Utilizing dextran-conjugated monoclonal anti-murine $\operatorname{IgD}$ molecules (antiIgD-dex) it was demonstrated that multivalent BCR cross linking alone, while inducing robust proliferation of resting $\mathrm{B}$ cells failed to induce antibody secretion [9]. However, antibody production was elicited upon addition of IL- 2 or IL- 5 to cultures of anti-IgD-dexactivated B cells. Since similar results were obtained upon measuring in vitro anti-trinitrophenyl (TNP) antibody responses to the TI antigen, TNP-Ficoll, it was proposed that anti-IgD-dex could serve as an in vitro model for TI responses.

Subsequent studies were designed to discover what additional "second signals" might co-stimulate Ig secretion and class switching in B cells activated through multivalent BCR cross-linking. The use of anti-IgD-dex to activate resting murine $\mathrm{B}$ cells in vitro allowed for the surprising discovery of new biologic activities of three cytokines: interferon-gamma (IFN- $\gamma$ ) [10], interleukin-3 (IL-3), and granulocyte-macrophage colony stimulating factor (GM-CSF) [11] Each of these cytokines were shown, for the first time, to induce large amounts of secreted IgM in anti-IgD-dextran-activated, but not CD40-ligand (CD40L)-activated, B cells in the presence of IL2. The addition of natural killer (NK) cells to cultures of murine $B$ cells activated with anti-IgD-dex + IL-2 also induced IgM secretion [12], through NK secretion of IFN- $\gamma$ [13]. Additional studies demonstrated that Toll-like receptor (TLR) ligands such as bacterial lipoproteins [14] and Neisserial porin protein [15] (TLR2), LPS (TLR4), and CpG-oligodeoxynucleotides (ODN) (TLR9) [16] could each act synergistically with anti-IgD-dex or anti-IgM-dex to induce large amounts of secreted IgM at concentrations of TLR ligands that by themselves induced only minimal secretion of antibody. Indeed, the combination of potent BCR stimulation using anti-Ig-dex and signaling mediated by TLR ligands could restore to essentially normal adults levels, the defective in vitro Ig secretory responses typically observed in neonatal B cells [17]. This observation has important implications for the design of vaccines targeted to the immature host. Further, when murine B cells were stimulated in vitro with anti-IgD-dex, the addition of ODN, even containing various non-optimal motifs, both methylated and non-methylated which ordinarily rendered them essentially non-functional for B cells, could nevertheless enhance proliferation and induce Ig secretion [18] Furthermore synergistic levels of proliferation were induced upon addition of functionally optimized ODN, in B cells activated with picomolar concentrations of anti-Ig-dex, that were 10- to 100 -fold less than previously reported to be necessary for mitogenic activity.

\section{Anti-Ig-dex co-stimulates Ig class switching in murine B cells in the presence of diverse stimuli}

Ig class switching is a process that can be directed by specific cytokines such as IL-4, IL-10, IFN- $\gamma$, and transforming growth factor- $\beta$ (TGF- $\beta$ ) [19]. Studies in mouse B cells utilizing anti-IgDdex demonstrated that Ig class switching in the presence of a specific cytokine or set of cytokines was critically influenced by the nature of the B cell activator (i.e. multivalent BCR cross linking versus activation via CD40 or with LPS). For example, whereas IL-4 induced class switching to IgE in murine B cells activated with CD40L or LPS, it failed to do so in anti-IgD-dex-activated $\mathrm{B}$ cells, even though all three modes of activation led to IL-4-mediated switching to IgG1 [20]. Further IFN- $\gamma$ induced switching to both $\operatorname{IgG} 3$ and $\operatorname{IgG} 2 \mathrm{a}$ in antiIgD-dex-activated B cells, whereas in LPS-activated B cells it induced switching to IgG2a but inhibited switching to IgG3 [21]. Finally, addition of anti-IgD-dex to cultures of B cells stimulated with LPS + IL- $4+$ IL-5+ TGF- $\beta$ established a useful model system for generating high levels of class switching to IgA in vitro [22] and studying the molecular mechanism by which this occurred [23]. The requirement for IL-5 for inducing switching to IgG1 in B cells activated with antiIgD-dex + IL-4, suggested a novel role for IL- 5 in the mechanism of class switching that was based on an unidentified mechanism distinct from the regulation of germline constant heavy gene transcription $[24,25]$. Although most studies on BCR-dependent Ig class switching employed anti-IgM-dex or anti-IgD-dex, one study utilized anti-IgAdex to demonstrate a selective defect in BCR-mediated activation in post-switched $(\operatorname{IgM}-\operatorname{IgA}+)$ as opposed to non-switched $(\operatorname{IgM}+\operatorname{IgD}+)$ $B$ cells [26]. Of interest, an alternate model of highly efficient polyclonal B cell multivalent BCR cross linking analogous to that based on anti-Ig-dex, was established by binding multiple copies of mouse IgG2a anti-mouse IgD to Chinese hamster ovary (CHO) cells permanently transfected with mouse Fc $\gamma$ RIa [27]. Similar to results using anti-Ig-dex [20], addition of IL-4 + IL-5 to cultures of B cells activated with $\mathrm{CHO}$-anti-mouse IgD induced switching to IgG1, but not IgE. A detailed review outlining specific methods for studying in vitro murine $\mathrm{B}$ cell activation, Ig secretion and Ig class switching using anti-Ig-dex, cytokines and TLR ligands has recently been published [28].

\section{The use of anti-Ig-dex to study the molecular mechanisms of Ig class switching in mouse $B$ cells}

An extensive number of published studies from the laboratory of J. Stavnezer [29-40] made critical use of anti-Ig-dex to study the molecular mechanisms underlying the immunoglobulin class switch in mouse B cells. Anti-Ig-dex was previously found to be a critical component in co-stimulating high-rate switching to IgA [22]. It was subsequently demonstrated that high doses of anti-Ig-dex could substitute for IL- $4+$ IL- 5 in promoting optimal TGF- $\beta$-dependent IgA switching, and that anti-Ig-dex correspondingly inhibited TGF$\beta$-mediated switching to IgG2b [30]. Anti-Ig-dex was also added to $B$ cell cultures stimulated with either LPS + BlyS for switching to IgG3 or LPS + BLyS + IL- 4 + IL- 5 + TGF- $\beta$ for switching to IgA, to study activation-induced cytidine deaminase (AID)-dependent DNA breaks, which were found to occur during the G1 phase of the cell cycle [29]. The same approach was used to demonstrate the enhancing effects of reactive oxygen species (ROS) on Ig class switching [35], but that did not depend on the DNA glycosylases Ogg1 and Nth1 that were hypothesized to be critical for class switching through their ability to excise ROS-induced oxidized bases [31]. Anti-Ig-dex was further used to enhance class switching to IgG3 in LPS + BLySactivated B cells, and to IgG1 in B cells stimulated with LPS + BLyS + IL-4 to demonstrate the requirement of the C-terminus of AID to cooperatively bind several enzymes (uracil-N-glycosylase 2 [UNG] and the mismatch repair proteins, Msh2-Msh6 heterodimer) critical for mediating Ig class switching [32]. Of note, the use of LPS + BLyS + anti-Ig-dex showed that AID could also induce DNA breaks at many non-Ig loci in B cells undergoing Ig class switching [33]. Further in vitro studies using anti-Ig-dex-dependent switching systems made the novel observation that double-stranded DNA breaks, critical for the process of class switching was dependent on apurinic/apyrimidinic endonuclease (APE1 and APE2) [34] and also demonstrated an endogenous role for the DNA repair enzyme, DNA polymerase $\beta$, in partially inhibiting Ig class switching, by replacing the deaminated cytosine induced by AID [36]. Finally, an enzyme involved in the 
repair of DNA damage, ATM (Ataxia-telangiectasia mutated), was shown to be important in promoting class switching in anti-Ig-dexcontaining B cell cultures, by increasing targeting and activity of AID at downstream acceptor switch regions [40].

Further studies from the laboratory of P. Casali also utilized antiIg-dex to study the molecular biology of the Ig class switch [41-45]. A mechanistic underpinning to the earlier studies from the laboratory of C. Snapper (see above) demonstrating marked synergy between anti-Ig-dex and various TLR-ligands for IgM and IgG secretion was elucidated. Thus, anti-Ig-dex was shown to induce the non-canonical NF- $\kappa B$ pathway that enhanced the TLR-dependent canonical NF- $\kappa B$ pathway for induction of the enzyme AID, critical for class switching [38]. Stimulation of murine B cells with LPS + IL- 4 + IL-5 + TGF- $\beta$ + anti-Ig-dex to induce high-rate switching to $\operatorname{IgA}[22]$ was part of a study demonstrating that AID associates with 14-3-3 adaptor proteins which bind to 5'-AGCT-3' repeats in switch regions, thus targeting AID for induction of class switch recombination [41]. Using this system, it was further demonstrated that AID induction was critically dependent on a homeodomain transcription factor, HoxC4, which bound to a highly conserved HoxC4-Oct site in the AID gene (Aicda) promoter [42]. Of note, estrogen-estrogen receptor complexes could bind to estrogen response elements in the HoxC4 promoter and induce AID and thus class switching [43]. Finally, it was demonstrated that AID-mediated deamination of cytosine could be inhibited specifically by bivalent iron ion $\left(\mathrm{Fe}^{2+}\right.$, ferrous) with an associated inhibition of class switching [44].

\section{Utilization of anti-human Ig-dex for studies of BCR signaling in human B cells}

In addition to multiple studies on murine B cells using antimurine Ig-dex, human B cell activation through multivalent BCR cross linking has also been extensively studied using anti-human Ig-dex conjugates. A direct comparison of dextran-conjugated and unconjugated anti-human IgM antibodies on human B cells led to the conclusion that highly multimeric $\mathrm{T}$ cell-independent antigens may be especially potent immunogens because they are able to elicit a full activation response from both infrequent high affinity $\mathrm{B}$ cells, as well as a substantial proportion of lower affinity antigen-specific B cells [46]. A greater potential of anti-IgM-dex to trigger entry into S-phase in the absence of cytokines was found to reflect its greater potential for initiating BCR-induced signals during the late phase in B cell activation [47]. Both high valency and affinity for IgM engagement also resulted in a greater degree of B cell apoptosis [48]. In studies of human B cell chronic lymphocytic leukemia (B-CLL) cells, cross linking of BCR with a monoclonal anti-human IgM-dex induced higher levels of PI3K/Akt-dependent telomerase activity, cell survival, and proliferation, relative to unconjugated anti-IgM antibody [49] Normal human B cells also exhibited a higher level of proliferation and survival with anti-IgM-dex relative to unconjugated anti-IgM. Neonatal cord blood human B cells also proliferated in response to 10,000-fold lower concentrations of anti-human Ig-dextran relative to unconjugated anti-Ig, at levels comparable to that observed with adult B cells [50]. The majority of cord blood B cells showed a marked rise in intracellular calcium, increased surface expression of human leukocyte antigen DR, and an increase in cell size. Thus, anti-Ig-dex can be used as a physiologic model to study the unique activation requirements of $\mathrm{B}$ cells from the immature host, with important implications for future design of vaccines targeting the infant population. A series of studies employed dextran conjugates to which both anti-human IgM and anti-human CD21 were co-conjugated, in order to study the functional consequences of BCR/CD21 co-ligation in human B cells [51-53]. Finally, anti-human Ig-dex has shown clinical applications by demonstrating that patients contracting meningococcal disease, despite earlier receiving the meningococcal serogroup $\mathrm{C}$ polysaccharide conjugate vaccine, had normal B cell responsiveness to anti-Ig-dex, a mimic of polysaccharide-induced $\mathrm{B}$ cell activation, but did have defects in CD4+ T cell help for B cells [54]. Similarly, patients who exhibited rapidly waning levels of serum antibodies specific for meningococcal serogroup C polysaccharide following vaccination with the conjugate vaccine, demonstrated normal responses to anti-Ig-dex, arguing against a direct B cell defect to explain this observation [55].

\section{References}

1. Brunswick M, Finkelman FD, Highet PF, Inman JK, Dintzis HM, et al. (1988) Picogram quantities of anti-lg antibodies coupled to dextran induce B cell proliferation. J Immunol 140: 3364-3372.

2. Mond JJ, Lees A, Snapper CM (1995) T cell-independent antigens type 2. Annu Rev Immunol 13: 655-692.

3. Harwood NE, Batista FD (2008) New insights into the early molecular events underlying B cell activation. Immunity 28: 609-619.

4. Brunswick M, June CH, Finkelman FD, Dintzis HM, Inman JK, et al. (1989) Surface immunoglobulin-mediated B-cell activation in the absence of detectable elevations in intracellular ionized calcium: a model for T-cellindependent B-cell activation. Proc Natl Acad Sci U S A 86: 6724-6728.

5. Brunswick M, June CH, Finkelman FD, Mond JJ (1989) Different patterns of inositol polyphosphate production are seen in B lymphocytes after crosslinking of slg by anti-lg antibody or by a multivalent anti-lg antibody dextran conjugate. J Immunol 143: 1414-1421.

6. Rehe GT, Katona IM, Brunswick M, Wahl LM, June CH, et al. (1990) Activation of human $B$ lymphocytes by nanogram concentrations of anti-lgMdextran conjugates. Eur J Immunol 20: 1837-1842.

7. Dintzis HM, Dintzis RZ, Vogelstein B (1976) Molecular determinants of immunogenicity: the immunon model of immune response. Proc Natl Acad Sci U S A 73: 3671-3675.

8. Dintzis RZ, Vogelstein B, Dintzis HM (1982) Specific cellular stimulation in the primary immune response: experimental test of a quantized model. Proc Natl Acad Sci U S A 79: 884-888.

9. Pecanha LM, Snapper CM, Finkelman FD, Mond JJ (1991) Dextranconjugated anti-Ig antibodies as a model for T cell-independent type 2 antigenmediated stimulation of Ig secretion in vitro. I. Lymphokine dependence. J Immunol 146: 833-839.

10. Snapper CM, Rosas F, Moorman MA, Jin L, Shanebeck K, et al. (1996) IFN-g is a potent inducer of $\mathrm{Ig}$ secretion by sort-purified murine $B$ cells activated through the mlg, but not the CD40, signaling pathway. Int Immunol 8: 877885.

11. Snapper CM, Moorman MA, Rosas FR, Kehry MR, Maliszewski CR, et al. (1995) IL-3 and Granulocyte-macrophage colony-stimulating factor strongly induce Ig secretion by sort-purified murine B cells activated through the membrane Ig, but not the CD40, signaling pathway. J Immunol 154: 5842 5850.

12. Snapper CM, Yamaguchi H, Moorman MA, Mond JJ (1994) An in vitro model for $\mathrm{T}$ cell-independent induction of humoral immunity. A requirement for NK cells. J Immunol 152: 4884-4892.

13. Vos Q, Snapper CM, Mond JJ (1999) Heterogeneity in the ability of cytotoxic murine NK cell clones to enhance Ig secretion in vitro. Int Immunol 11: 159168.

14. Snapper CM, Rosas FR, Jin L, Wortham C, Kehry MR, et al. (1995) Bacterial lipoproteins may substitute for cytokines in the humoral immune response to T cell-independent type II antigens. J Immunol 155: 5582-5589.

15. Snapper CM, Rosas FR, Kehry MR, Mond JJ, Wetzler LM (1997) Neisserial porins may provide critical second signals to polysaccharide-activated murine B cells for induction of immunoglobulin secretion. Infect Immun 65: 32033208.

16. Snapper CM, Mond JJ (1993) Towards a comprehensive view of immunoglobulin class switching. Immunol Today 14: 15-17.

17. Snapper CM, Rosas FR, Moorman MA, Mond JJ (1997) Restoration of T cell-independent type 2 induction of Ig secretion by neonatal B cells in vitro. J Immunol 158: 2731-2735.

18. Goeckeritz BE, Flora M, Witherspoon K, Vos Q, Lees A, et al. (1999) Multivalent cross-linking of membrane lg sensitizes murine $B$ cells to a broader spectrum of CpG-containing oligodeoxynucleotide motifs, including their methylated counterparts, for stimulation of proliferation and Ig secretion. Int Immunol 11: 1693-1700.

19. Stavnezer J, Schrader CE (2014) IgH chain class switch recombination: mechanism and regulation. J Immunol 193: 5370-5378.

20. Snapper CM, Peçanha LM, Levine AD, Mond JJ (1991) lgE class switching is critically dependent upon the nature of the $B$ cell activator, in addition to the presence of IL-4. J Immunol 147: 1163-1170.

21. Snapper CM, Mclntyre TM, Mandler R, Pecanha LM, Finkelman FD, et al. (1992) Induction of IgG3 secretion by interferon gamma: a model for $T$ cell-independent class switching in response to $T$ cell-independent type 2 antigens. J Exp Med 175: 1367-1371. 
22. Mclntyre TM, Kehry MR, Snapper CM (1995) Novel in vitro model for highrate IgA class switching. J Immunol 154: 3156-3161.

23. Bradley SP, Kaminski DA, Peters AH, Jenuwein T, Stavnezer J (2006) The histone methyltransferase Suv39h1 increases class switch recombination specifically to IgA. J Immunol 177: 1179-1188.

24. Mandler R, Chu CC, Paul WE, Max EE, Snapper CM (1993) Interleukin 5 induces $\mathrm{Sm}-\mathrm{Sg} 1 \mathrm{DNA}$ rearrangement in B cells activated with dextran-antiIgD antibodies and interleukin 4: A three component model for Ig class switching. J Exp Med 178: 1577-1586.

25. Snapper CM, Marcu KB, Zelazowski P (1997) The immunoglobulin class switch: beyond "accessibility". Immunity 6: 217-223.

26. Ehrhardt RO, Harriman GR, Inman JK, Lycke N, Gray B, et al. (1996) Differential activation requirements of isotype-switched B cells. Eur J Immunol 26: $1926-1934$

27. Cho S, Conrad DH (1997) A new multivalent B cell activation model--anti-lgD bound to Fc gamma RI: properties and comparison with CD40L-mediated activation. Int Immunol 9: 239-248.

28. Pone EJ (2016) Analysis by Flow Cytometry of B-Cell Activation and Antibody Responses Induced by Toll-Like Receptors. Methods Mol Biol 1390: 229-248.

29. Schrader CE, Guikema JE, Linehan EK, Selsing E, Stavnezer J (2007) Activation-induced cytidine deaminase-dependent DNA breaks in class switch recombination occur during G1 phase of the cell cycle and depend upon mismatch repair. J Immunol 179: 6064-6071.

30. Kaminski DA, Stavnezer J (2007) Stimuli that enhance IgA class switching increase histone 3 acetylation at $S$ alpha, but poorly stimulate sequential switching from IgG2b. Eur J Immunol 37: 240-251.

31. Ucher AJ, Linehan EK, Teebor GW, Schrader CE, Stavnezer J (2012) The DNA glycosylases Ogg1 and Nth1 do not contribute to Ig class switching in activated mouse splenic B cells. PLoS One 7: e36061.

32. Ranjit S, Khair L, Linehan EK, Ucher AJ, Chakrabarti M, et al. (2011) AID recruits UNG and Msh2 to Ig switch regions dependent upon the AID C terminus [corrected]. J Immunol 187: 2464-2475

33. Staszewski O, Baker RE, Ucher AJ, Martier R, Stavnezer J, et al. (2011) Activation-induced cytidine deaminase induces reproducible DNA breaks at many non-Ig Loci in activated B cells. Mol Cell 41: 232-242.

34. Guikema JE, Linehan EK, Tsuchimoto D, Nakabeppu Y, Strauss PR, et al (2007) APE1- and APE2-dependent DNA breaks in immunoglobulin class switch recombination. J Exp Med 204: 3017-3026.

35. Guikema JE, Schrader CE, Brodsky MH, Linehan EK, Richards A, et al. (2010) p53 represses class switch recombination to $\operatorname{lgG} 2 a$ through its antioxidant function. J Immunol 184: 6177-6187.

36. Wu X, Stavnezer J (2007) DNA polymerase beta is able to repair breaks in switch regions and plays an inhibitory role during immunoglobulin class switch recombination. J Exp Med 204: 1677-1689.

37. Haddad D, Oruc Z, Puget N, Laviolette-Malirat N, Philippe M, et al. (2011) Sense transcription through the $S$ region is essential for immunoglobulin class switch recombination. EMBO J 30: 1608-1620.

38. Pone EJ, Zhang J, Mai T, White CA, Li G, et al. (2012) BCR-signalling synergizes with TLR-signalling for induction of AID and immunoglobulin class-switching through the non-canonical NF-kB pathway. Nat Commun 3 : 767

39. Vuong BQ, Herrick-Reynolds K, Vaidyanathan B, Pucella JN, Ucher AJ, et al. (2013) A DNA break- and phosphorylation-dependent positive feedback loop promotes immunoglobulin class-switch recombination. Nat Immunol 14 $1183-1189$.
40. Khair L, Guikema JE, Linehan EK, Ucher AJ, Leus NG, et al. (2014) ATM increases activation-induced cytidine deaminase activity at downstream $S$ regions during class-switch recombination. J Immunol 192: 4887-4896.

41. Xu Z, Fulop Z, Wu G, Pone EJ, Zhang J, et al. (2010) 14-3-3 adaptor proteins recruit AID to 5'-AGCT-3'-rich switch regions for class switch recombination. Nat Struct Mol Biol 17: 1124-1135.

42. Park SR, Zan H, Pal Z, Zhang J, Al-Qahtani A, et al. (2009) HoxC4 binds to the promoter of the cytidine deaminase AID gene to induce AID expression, class-switch DNA recombination and somatic hypermutation. Nat Immunol 10: $540-550$

43. Mai T, Zan H, Zhang J, Hawkins JS, Xu Z, et al. (2010) Estrogen receptors bind to and activate the HOXC4/HoxC4 promoter to potentiate HoxC4mediated activation-induced cytosine deaminase induction, immunoglobulin class switch DNA recombination, and somatic hypermutation. J Biol Chem 285: $37797-37810$

44. Li G, Pone EJ, Tran DC, Patel PJ, Dao L, et al. (2012) Iron inhibits activationinduced cytidine deaminase enzymatic activity and modulates immunoglobulin class switch DNA recombination. J Biol Chem 287: 21520-21529.

45. Li G, White CA, Lam T, Pone EJ, Tran DC, et al. (2013) Combinatoria $\mathrm{H} 3 \mathrm{~K} 9 \mathrm{acS} 10$ ph histone modification in IgH locus $\mathrm{S}$ regions targets 14-3-3 adaptors and AID to specify antibody class-switch DNA recombination. Cell Rep 5: 702-714.

46. Mongini PKA, Blessinger CA, Highet PF, Inman JK (1992) Membrane IgMmediated signaling of human B cells. Effect of increase ligand binding site valency on the affinity and concentration requirements for inducing diverse stages of activation. J Immunol 148: 3892-3901.

47. Mongini PK, Highet PF, Inman JK (1995) Human B cell activation. Effect of $T$ cell cytokines on the physicochemical binding requirements for achieving cell cycle progression via the membrane IgM signaling pathway. J Immunol 155: 3385-3400.

48. Mongini PK, Vilensky MA, Highet PF, Inman JK (1998) Membrane IgMstimulated human $B$ lymphocytes succumb to activation-related apoptosis at a G1-->S transition: influence of ligand affinity and valency. Cell Immunol 188: $137-150$.

49. Damle RN, Temburni S, Banapour T, Paul S, Mongini PK, et al. (2012) T-cell independent, B-cell receptor-mediated induction of telomerase activity differs among IGHV mutation-based subgroups of chronic lymphocytic leukemia patients. Blood 120: 2438-2449.

50. Halista SM, Johnson-Robbins LA, El-Mohandes AE, Lees A, Mond JJ, et al. (1998) Characterization of early activation events in cord blood B cells afte stimulation with T cell-independent activators. Pediatr Res 43: 496-503.

51. Mongini PK, Jackson AE, Tolani S, Fattah RJ, Inman JK (2003) Role of complement-binding CD21/CD19/CD81 in enhancing human B cell protection from Fas-mediated apoptosis. J Immunol 171: 5244-5254.

52. Mongini PK, Tolani S, Fattah RJ, Inman JK (2002) Antigen receptor triggered upregulation of CD86 and CD80 in human B cells: augmenting role of the CD21/CD19 co-stimulatory complex and IL-4. Cell Immunol 216: 50-64.

53. Mongini PK, Inman JK (2001) Cytokine dependency of human B cell cycle progression elicited by ligands which coengage BCR and the CD21/CD19/ CD81 costimulatory complex. Cell Immunol 207: 127-140.

54. Foster RA, Carlring J, Lees A, Borrow R, Ramsay M, et al. (2010) Functional $T$-cell deficiency in adolescents who experience serogroup $C$ meningococcal disease despite receiving the meningococcal serogroup $C$ conjugate vaccine. Clin Vaccine Immunol 17: 1104-1110.

55. Wing JB, Smart L, Borrow R, Findlow J, Findlow H, et al. (2012) Correlation of group $C$ meningococcal conjugate vaccine response with $\mathrm{B}$ - and T-lymphocyte activity. PLoS One 7: e31160. 